\title{
Adjusting the Structure of $\beta$-Cyclodextrin to Improve Complexation of Anthraquinone-Derived Drugs
}

\author{
Agata Krzak ${ }^{1,2}$, Olga Swiech ${ }^{1,2, * \mathbb{D}}$, Maciej Majdecki ${ }^{3}$, Piotr Garbacz ${ }^{1}$, Paulina Gwardys ${ }^{1}$ \\ and Renata Bilewicz $1,2, *$ iD \\ 1 Faculty of Chemistry, University of Warsaw, Pasteura 1, 02093 Warsaw, Poland; \\ agata.krzak@chem.uw.edu.pl (A.K.); pgarbacz@chem.uw.edu.pl (P.G.); p.gwardys2@student.uw.edu.pl (P.G.) \\ 2 Faculty of Chemistry, Biological and Chemical Research Centre, University of Warsaw, Żwirki i Wigury 101, \\ 02089 Warsaw, Poland \\ 3 Institute of Organic Chemistry, Polish Academy of Sciences, Kasprzaka 44/52, 01224 Warsaw, Poland; \\ mmajdecki@icho.edu.pl \\ * Correspondence: oswiech@chem.uw.edu.pl (O.S.); bilewicz@chem.uw.edu.pl (R.B.)
}

\section{check for}

updates

Citation: Krzak, A.; Swiech, O.; Majdecki, M.; Garbacz, P.; Gwardys, P.; Bilewicz, R. Adjusting the Structure of $\beta$-Cyclodextrin to Improve Complexation of Anthraquinone-Derived Drugs. Molecules 2021, 26, 7205. https:// doi.org/10.3390/molecules26237205

Academic Editors: Igor Alabugin, M. Amparo F. Faustinon and Ionel Mangalagiu

Received: 19 September 2021 Accepted: 24 November 2021 Published: 27 November 2021

Publisher's Note: MDPI stays neutral with regard to jurisdictional claims in published maps and institutional affiliations.

Copyright: (c) 2021 by the authors. Licensee MDPI, Basel, Switzerland. This article is an open access article distributed under the terms and conditions of the Creative Commons Attribution (CC BY) license (https:// creativecommons.org/licenses/by/ $4.0 /)$.

\begin{abstract}
Cyclodextrin (CD) derivatives containing an aromatic triazole ring were studied as potential carriers of the following drugs containing an anthraquinone moiety: anthraquinone-2sulfonic acid (AQ2S); anthraquinone-2-carboxylic acid (AQ2CA); and a common anthracycline, daunorubicin (DNR). UV-Vis and voltammetry measurements were carried out to determine the solubilities and association constants of the complexes formed, and the results revealed the unique properties of the chosen $\mathrm{CDs}$ as effective $\mathrm{pH}$-dependent drug complexing agents. The association constants of the drug complexes with the CDs containing a triazole and lipoic acid ( $\beta C D L i p)$ or galactosamine ( $\beta C D G A L)$, were significantly larger than that of the native $\beta C D$. The AQ2CA and AQ2S drugs were poorly soluble, and their solubilities increased as a result of complex formation with $\beta C D L i p$ and $\beta C D G A L$ ligands. AQ2CA and AQ2S are negatively charged at $\mathrm{pH}$ 7.4. Therefore, they were less prone to form an inclusion complex with the hydrophobic $\mathrm{CD}$ cavity than at $\mathrm{pH} 3$ (characteristic of gastric juices) when protonated. The $\beta C D$ Triazole and $\beta C D G A L$ ligands were found to form weaker inclusion complexes with the positively charged drug DNR at an acidic $\mathrm{pH}$ ( $\mathrm{pH}$ 5.5) than in a neutral medium ( $\mathrm{pH}$ 7.4) in which the drug dissociates to its neutral, uncharged form. This $\mathrm{pH}$ dependence is favorable for antitumor applications.
\end{abstract}

Keywords: cyclodextrins; anthraquinone-2-sulfonic acid; anthraquinone-2-carboxylic acid; daunorubicin; association constant; solubility; inclusion complex

\section{Introduction}

Anthraquinone (AQ) derivatives constitute a large and diverse group, many of which have therapeutic properties and are used as chemotherapeutic [1,2], antiviral [3], immune boosting [4], or anti-inflammatory agents [5]. They are considered to be promising scaffolds for the development of antiviral drugs against SARS-CoV-2 [6,7]. They are also used as laxatives [8] for the treatment of malaria [9,10] and multiple sclerosis [11]. 6-Methyl-1,3,8-trihydroxyanthraquinone (emodine) has been investigated for the treatment of neurodegenerative diseases, and it has been reported to inhibit the pathological aggregation of tau protein. It was shown to protect against beta-amyloid-induced or $\mathrm{H}_{2} \mathrm{O}_{2}$-induced cortical neuronal deaths [12-15]. The synthetic quinone anthraquinone-2sulfonic acid (AQ2S, Figure 1) studied in this work has an especially strong protective effect toward primary neurons, and the neuroprotective mechanisms of AQ2S are related to caspase inhibition [16]. Another drug, anthraquinone-2-carboxylic acid (9,10-dihydro9,10-dioxo-2-anthracenecarboxylic acid (AQ2CA, Figure 1), has been shown to alleviate various inflammatory and pain symptoms, including $\mathrm{EtOH} / \mathrm{HCl}$ and acetylsalicylic acid (ASA) gastritis, as well as inhibit the expression of inflammatory genes; it also acts as a 
potent anti-inflammatory ingredient in vivo, contributing to the regulation of the immune system [17].<smiles>[R]c1ccc2c(c1)C(=O)c1ccccc1C2=O</smiles>

AQ2CA: $\quad \mathrm{R}-\mathrm{COOH}$

AQ2S: $\quad \mathrm{R}-\mathrm{SO}_{3} \mathrm{Na}$<smiles>COc1cccc2c1C(=O)c1c(O)c3c(c(O)c1C2=O)CC(O)(C(C)=O)CC3OC1C[C@@H]([NH3+])[C@H](C)[C@H](O)[C@H]1O[NH3+]</smiles>

Figure 1. Structures of anthraquinone-2-sulfonic acid (AQ2S), anthraquinone-2-carboxylic acid (AQ2CA), and daunorubicin (DNR).

Anthracyclines represent a distinct group of anthraquinone derivatives used to treat various types of cancer. The most popular representatives of anthracyclines, daunorubicin (DNR, Figure 1) and doxorubicin, are among the most effective anticancer drugs so far. They are used, among others, in the treatment of acute lymphocytic and myeloid leukemias, lymphomas, and bladder, breast, and brain cancer [18-20]. The cytostatic and cytotoxic effects of anthracyclines are explained by different mechanisms, including their interaction with topoisomerase II, which promotes growth arrest and apoptotic death of the tumor cells. It is also known that the anthraquinone moiety in anthracyclines intercalates between adjacent DNA base pairs, which leads to the inhibition of DNA and RNA synthesis, especially in highly replicating cells [21].

Despite the wide range of applications of anthraquinone-based pharmaceuticals, these drugs also have serious limitations as they have negative side effects during therapy [22]. They have the ability to generate reactive oxygen species (ROS) in the presence of cytochrome P450 reductase, NADH dehydrogenase, and xanthine oxidase (Scheme S1, Supplementary Materials). The excess ROS cannot be detoxified, which causes oxidative stress, DNA damage, and lipid peroxidation, thereby triggering cell apoptosis. Whereas this is a minor process for cancer cells, ROS also damages healthy tissues in the body. The most dangerous side effect of anthracyclines is cardiotoxicity [23,24].

Another disadvantage of anthraquinone-based drugs is their limited solubility in aqueous solutions [25]. The presence of hydrophilic substituents such as sugars may improve solubility; however, the therapeutic properties of these drugs are also changed. The solubility depends on the $\mathrm{pH}$ of the solution, leading to reduced absorption of drugs, and thus reduced bioavailability and therapeutic effect [26].

These negative properties of anthraquinone derivatives, i.e., poor solubility and the production of reactive oxygen species, can be improved by encapsulating the drug molecules in carriers $[27,28]$, for example, binding them in the cavities of cyclic oligosaccharides, i.e., cyclodextrins (CD). The CD structure with its hydrophobic cavity allows the formation of an inclusion complex with hydrophobic drugs (Figure 2). Additionally, the presence of free hydroxyl groups outside the oligosaccharide ring allows CDs to be modified with substituents that influence the strength of drug binding [29,30]. In our previous work, we proved that properly modified cyclodextrins can increase the stability and solubility of poorly soluble drugs, based on the example of temozolomide [31]. 


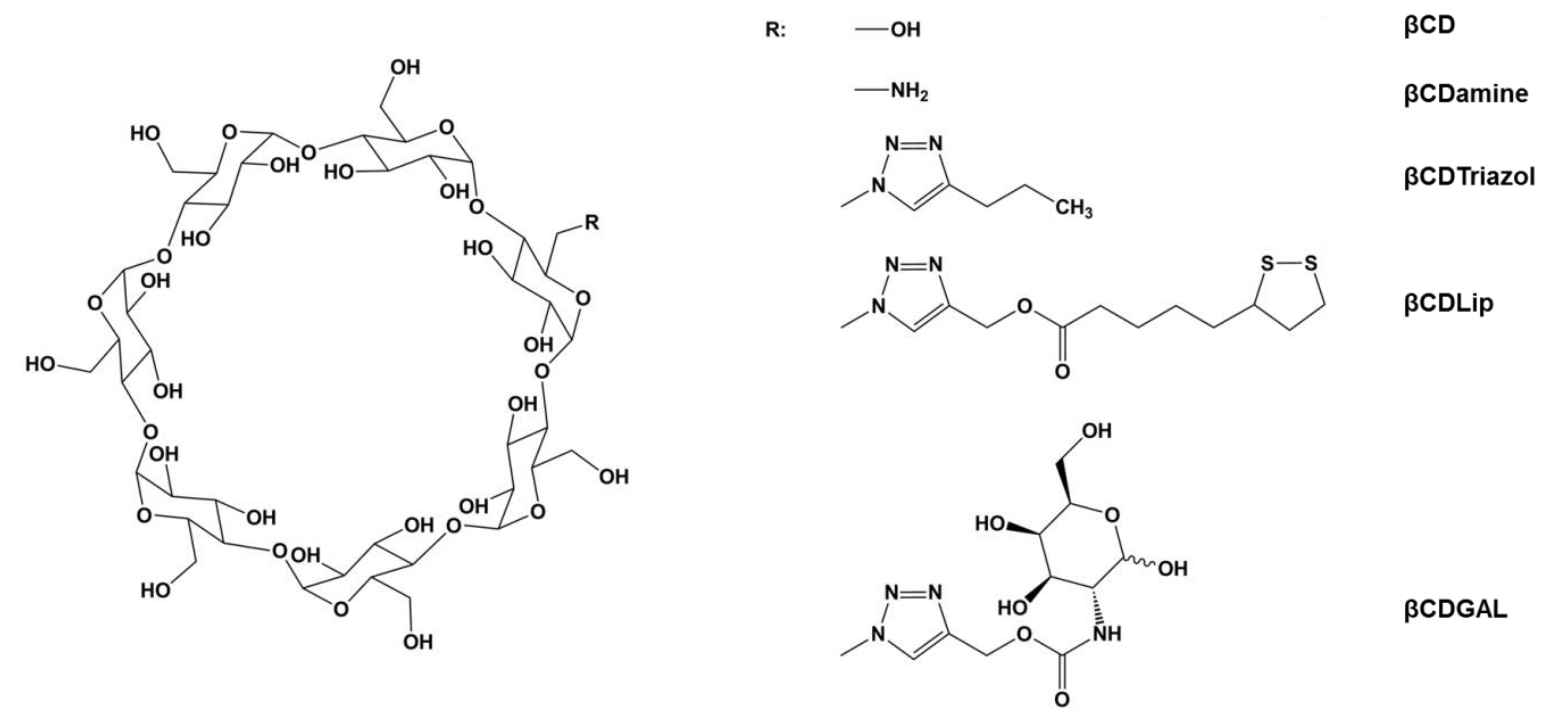

Figure 2. Structures of $\beta$-cyclodextrin and its derivatives used in the present work.

In this work, we show that by using appropriate CD derivatives as carriers of anthraquinone-based drugs (Figure 2) we can both improve the solubility of the drug and increase the strength of the complex with the drug, paving the way to a reduction in unwanted side effects of these drugs connected with ROS production, as well as membrane permeability and solubility limitations. Moreover, NMR measurements for investigation of the $\beta C D$ complexes binding site were performed and the $\mathrm{pKa}$ values for three cyclodextrin derivatives containing the triazole linker were determined. The presence of different kinds of substituents on the side chain of the triazole ring has been shown to have no effect on the $\mathrm{pKa}$ value of triazole-modified cyclodextrin and the $\mathrm{pKa}$ value is 4.5 . We study three different guests (drugs) each of them containing an anthraquinone moiety. Depending on the $\mathrm{pH}$, these drugs occur in different forms (cationic, anionic, or neutral); therefore, our aim was to establish how different $\mathrm{pH}$ values and the resulting charge of the drug affect its interaction with the cyclodextrin derivative. Our studies reveal that the form of the drug does matters, i.e., the charge of the drug and of the ligand are crucial, since the presence of electrostatic interactions between oppositely charged guest and host strengthens the complexes with cyclodextrin derivatives containing the triazole linker.

\section{Results and Discussion}

\subsection{Determination of $p K a$ Values of $C D$ Derivatives}

Due to the fact that the triazole linker in CD derivatives contains a basic nitrogen atom that can be protonated at an acidic $\mathrm{pH}$, we determined the value of $\mathrm{pKa}$ by UV-Vis spectroscopy. The spectra of $\beta C D G A L, \beta C D L i p$, and $\beta C D T r i a z o l$, at the $\mathrm{pH}$ range between 2.7 and 9.5, are presented on Figure 3. The dependence of the absorbance of the peak maximum at wavelengths in the range of $210-220$ on the $\mathrm{pH}$ of the buffer is presented in the figures. According to the equation $\mathrm{pKa}=\left[\mathrm{CDH}^{+}\right]\left[\mathrm{H}^{+}\right] /[\mathrm{CD}]$ for equal concentrations of the protonated and deprotonated forms, $\mathrm{pKa}=\mathrm{pH}$; the $\mathrm{pKa}$ value, for all three derivatives containing the triazole linker, was determined to be 4.5 . Changing the CD substituent does not affect the acid dissociation constant of the triazole linker. A pKa value of 4.5 means that, at a $\mathrm{pH}$ below the $\mathrm{pKa}$ value, the CD derivative is usually in protonated form, and its additional positive charge in the triazole ring may affect the strength of the drug binding with the CD derivatives. For the amine derivative $C D$, the $\mathrm{pKa}$ value is available in the literature, and its value equal to 8.84 [32] does not affect the strength of the binding of this cyclodextrin with the drug at the range of physiological $\mathrm{pH}$ we tested. 

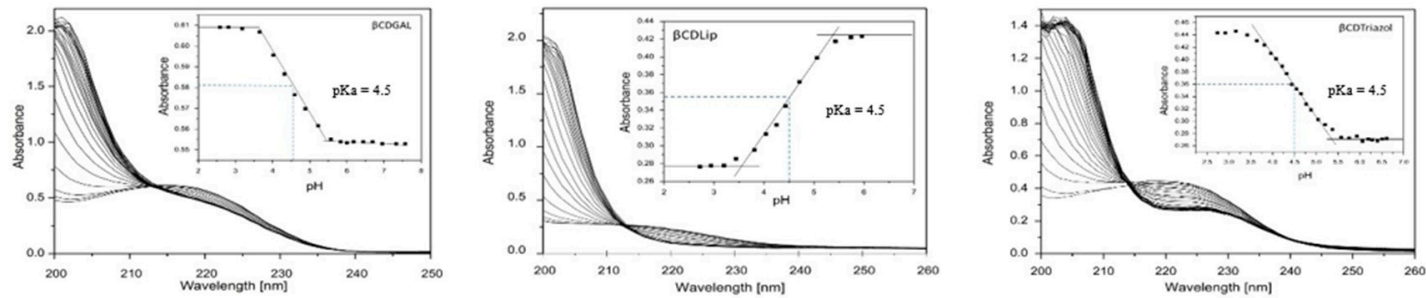

Figure 3. The UV-Vis spectra of (a) $\beta C D G A L,(b) \beta C D L i p$, and (c) $\beta C D$ Triazol at the $\mathrm{pH}$ range between 2.7 and 9.5. The dependences of the absorbance on the $\mathrm{pH}$ of the Britton-Robinson buffer are presented in the figures.

\subsection{Tuning $\beta$-Cyclodextrin Structure to Improve the Solubilities of AQ2CA and AQ2S Drugs}

Anthraquinone-2-carboxylic acid (AQ2CA) is a poorly water-soluble drug $\left(\mathrm{S}_{\mathrm{AQ2}} \mathrm{CA}\right.$ in water $\left.=3.98 \times 10^{-5} \mathrm{M}\right)$. The solubility of AQ2CA in Britton-Robinson buffer, $\mathrm{pH} 7.4$, is $1.74 \times 10^{-3} \mathrm{M}$, while that in acidic solution (Britton-Robinson buffer, $\mathrm{pH} 3.0$ ) is significantly lower $\left(\mathrm{S}_{\mathrm{AQ} 2 \mathrm{CA}}=1.43 \times 10^{-6} \mathrm{M}\right)$. An improvement in the aqueous solubility of AQ2CA would improve the biological availability of the drug. Such a drug solubilization effect was achieved via complexation using appropriate $C D$ derivatives. The phase solubility method developed by Higuchi and Connors was employed to quantify the solubilization ability of cyclodextrins [33]. The solubility values of AQ2CA in water, $\mathrm{BR}$ buffer at $\mathrm{pH} 7.4$ ( $\mathrm{pH}$ corresponding to the physiological conditions), and BR buffer at $\mathrm{pH}$ 3.0, with the addition of $\mathrm{CDs}$ was determined. The $\mathrm{pH}$ values characteristic for bodily fluids ( $\mathrm{pH} 7.4$ ) and for gastric juices $(\mathrm{pH} 3)$ were chosen for these measurements. The solubility diagrams (Figure 4) show that the solubility of anthraquinone-2-carboxylic acid increases linearly with an increase in cyclodextrin concentration (correlation coefficient > 0.99) up to $3 \mathrm{mM}$. According to the Higuchi and Connors classification [33], the phase solubility diagrams for anthraquinone-2-carboxylic acid with various cyclodextrin concentrations can be classified as $\mathrm{A}_{\mathrm{L}}$ type. The diagrams, with linear correlation and a slope lower than 1, are characteristic for 1:1 complexation between the guest (AQ2CA) and host (cyclodextrin) molecules, suggesting that a good-solubility AQ2CA-CD complex was formed in the solution. The most spectacular increase in solubility was obtained in the presence of $\beta C D L i p$ and $\beta C D G A L$ (almost tenfold increase in solubility at $\mathrm{pH}$ 3.0).

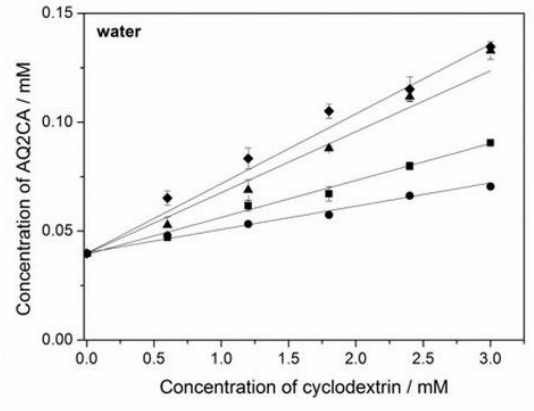

(a)

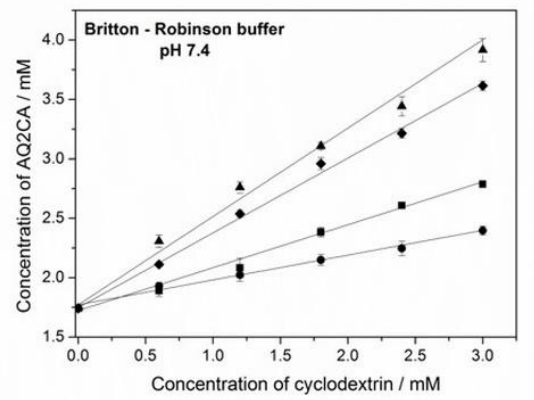

(b)

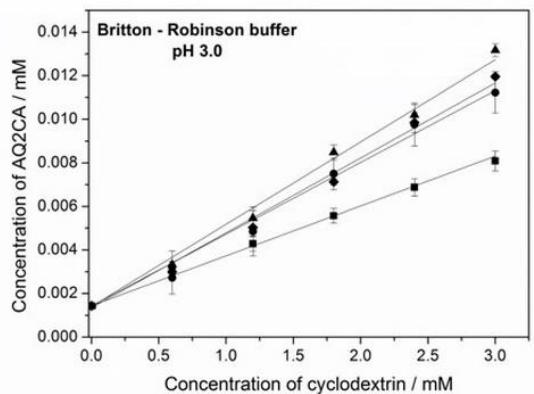

(c)

Figure 4. Phase solubility diagrams of the inclusion complexes of AQ2CA with $\beta C D(\boldsymbol{\square}), \beta C D a m i n e ~(\bullet), \beta C D L i p(\diamond)$, and $\beta C D G A L(\boldsymbol{\Lambda})$ in: (a) Water; (b) Britton-Robinson buffer at pH 7.4; (c) Britton-Robinson buffer at pH 3.0.

The association constant of the AQ2CA-cyclodextrin complex (1:1) was calculated from the linear plot of the phase solubility diagrams using Equation (1). The lines are started at the point of initial drug solubility, meaning, i.e., without the addition of cyclodextrin. The values of $\mathrm{K}_{1: 1}$, as well as the solubility increase and correlation coefficients of the phase solubility diagrams, are presented in Table 1. 
Table 1. Solubility increase (\%) of AQ2CA, association constant $\left(\mathrm{K}_{1: 1}\right)$ and correlation coefficient $\left(R^{2}\right)$ obtained from the AQ2CA-cyclodextrin phase solubility diagrams in water, Britton-Robinson buffer at $\mathrm{pH}$ 7.4, and Britton-Robinson buffer at $\mathrm{pH}$ 3.0.

\begin{tabular}{|c|c|c|c|}
\hline \multicolumn{4}{|c|}{ Water } \\
\hline Cyclodextrin & Solubility ${ }^{(a)}$ increase (\%) & $\mathrm{K}_{1: 1}\left(\mathrm{M}^{-1}\right)$ & $R^{2}$ \\
\hline$\beta C D$ & 128 & $460 \pm 45$ & 0.9911 \\
\hline$\beta C$ Damine & 77 & $280 \pm 30$ & 0.9900 \\
\hline$\beta C D L i p$ & 238 & $800 \pm 40$ & 0.9880 \\
\hline$\beta C D G A L$ & 234 & $840 \pm 45$ & 0.9896 \\
\hline \multicolumn{4}{|c|}{ Britton-Robinson Buffer pH 7.4} \\
\hline Cyclodextrin & Solubility ${ }^{(b)}$ increase (\%) & $\mathrm{K}_{1: 1}\left(\mathrm{M}^{-1}\right)$ & $R^{2}$ \\
\hline$\beta C D$ & 60 & $350 \pm 40$ & 0.9913 \\
\hline$\beta C$ Damine & 38 & $160 \pm 20$ & 0.9906 \\
\hline$\beta C D L i p$ & 108 & $940 \pm 25$ & 0.9961 \\
\hline$\beta C D G A L$ & 125 & $1300 \pm 60$ & 0.9932 \\
\hline \multicolumn{4}{|c|}{ Britton-Robinson Buffer pH 3.0} \\
\hline Cyclodextrin & Solubility ${ }^{(\mathrm{c})}$ increase $(\%)$ & $\mathrm{K}_{1: 1}\left(\mathrm{M}^{-1}\right)$ & $R^{2}$ \\
\hline$\beta C D$ & 464 & $1480 \pm 180$ & 0.9965 \\
\hline$\beta C$ Damine & 683 & $2450 \pm 200$ & 0.9910 \\
\hline$\beta C D L i p$ & 734 & $2520 \pm 175$ & 0.9940 \\
\hline$\beta C D G A L$ & 820 & $2760 \pm 110$ & 0.9945 \\
\hline
\end{tabular}

(a) Solubility in water without CDs- $0.01 \mathrm{mg} / \mathrm{mL}$; ${ }^{\text {(b) }}$ solubility in Britton-Robinson buffer, $\mathrm{pH} 7.4$ without CDs- $0.44 \mathrm{mg} / \mathrm{mL}$; ${ }^{(c)}$ solubility in Britton-Robinson buffer, $\mathrm{pH} 3.0$ without CDs- $0.00036 \mathrm{mg} / \mathrm{mL}$.

According to the phase solubility diagrams (Figure 4) and the association constant $\left(\mathrm{K}_{1: 1}\right)$ values (Table 1$), \beta C D L i p$ and $\beta C D G A L$ featured an enhanced solubilizing effect and tlarger association constants of the complexes formed with these ligands. Complexes with $\beta C D$ and $\beta C D a m i n e$ were weaker, especially in neutral solutions. The stronger $\beta C D L i p$ and $\beta C D G A L$ effect is related to the presence of an aromatic triazole ring in their structures, which contributes to the strengthening of the complex through proton-acceptor $\pi-\pi$ interactions with the aromatic ring of the drug [34]. These results confirm the beneficial effect achieved thanks to appropriate modification of the cyclodextrin. Larger association constants in the proton-rich environment $(\mathrm{pH} 3.0)$ are connected with the form of the drug. At $\mathrm{pH}$ 3.0, AQ2CA is in a neutral (protonated) form, whereas, at $\mathrm{pH} 7.4$, it is anionic. The lower association constants at $\mathrm{pH} 7.4$ reflect the lower affinity of the charged drug molecule to the hydrophobic cavity of the cyclodextrin.

The association constants of the AQ2CA- and AQ2S-cyclodextrin complexes were also determined by voltammetry using the Osa method (Equation (2)) in solutions of $\mathrm{pH} 3.0$ and 7.4. The cyclic voltammograms for $\mathrm{AQ2CA}$ and $\mathrm{AQ} 2 \mathrm{~S}$ recorded in the absence and presence of $\beta C D G A L$ are shown in Figure 5.

The addition of cyclodextrin to the AQ2CA or AQ2S solution led to a decrease in the voltammetric peak currents ascribed to the smaller diffusion coefficient of all drugcyclodextrin complexes as compared with that of the free drugs. The dependencies of $\mathrm{I}^{2}{ }_{\text {obs }}$ vs. $\left(\mathrm{I}^{2}{ }_{\text {drug }}-\mathrm{I}^{2}{ }_{\text {obs }}\right) /[\mathrm{CD}]$ for the AQ2CA-CD and AQ2S-CD complexes at $\mathrm{pH} 7.4$ and $\mathrm{pH} 3.0$ obtained using the CV method are shown in Figure 6. The values of the association constants for all complexes at pH 7.4 and 3.0 are exhibited in Table 2. 


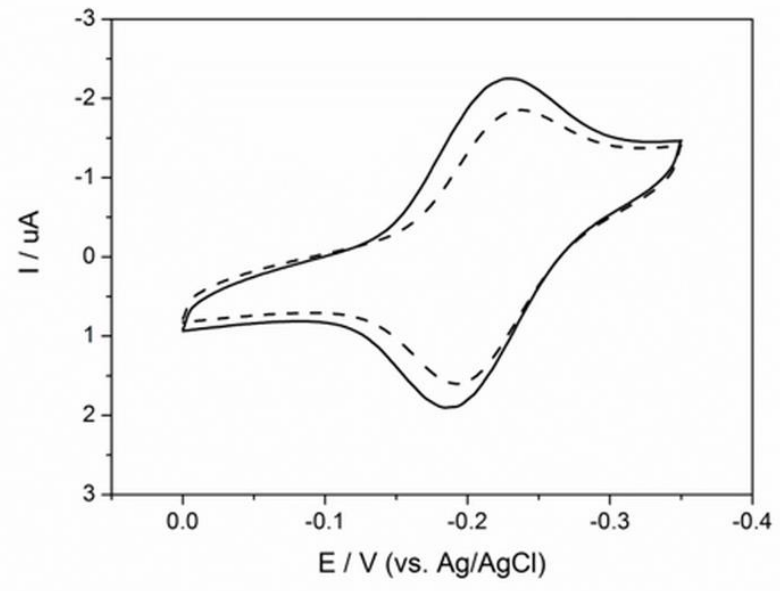

(a)

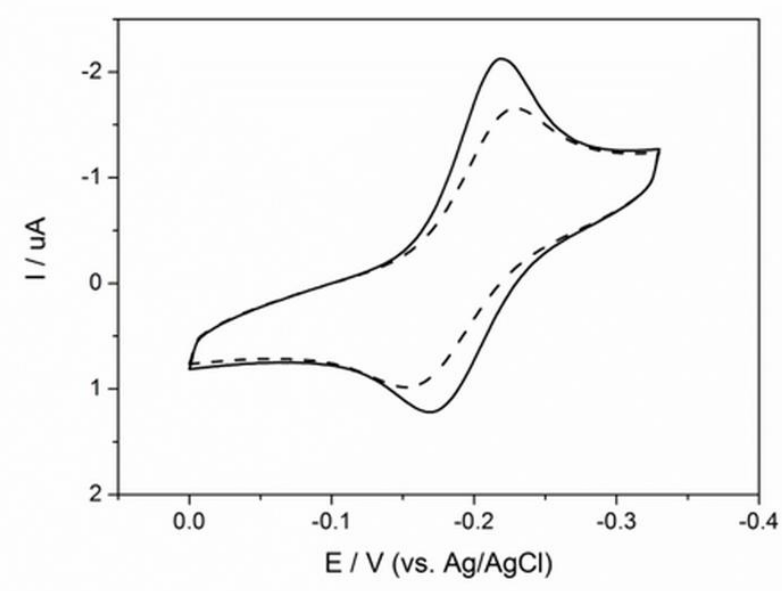

(b)

Figure 5. Cyclic voltammograms of $2.5 \times 10^{-5} \mathrm{M}$ (a) AQ2CA and (b) AQ2S in the absence (solid line) and presence of $1.08 \times 10^{-3} \mathrm{M} \beta \mathrm{CDGAL}$ (dashed line), recorded in BR buffer at $\mathrm{pH}$ 3.0. All potentials are reported vs. a silver/silver chloride $(\mathrm{Ag} / \mathrm{AgCl})$ electrode. Scan rate, $100 \mathrm{mV} \cdot \mathrm{s}^{-1}$.

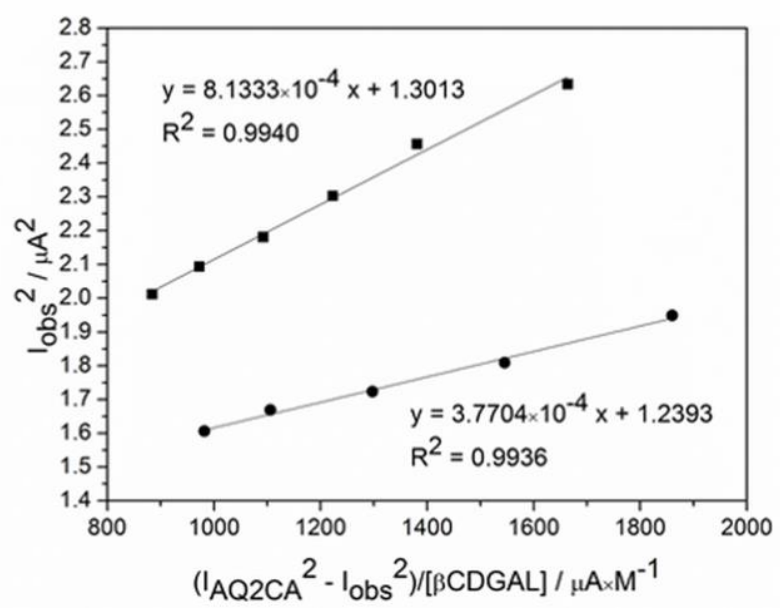

(a)

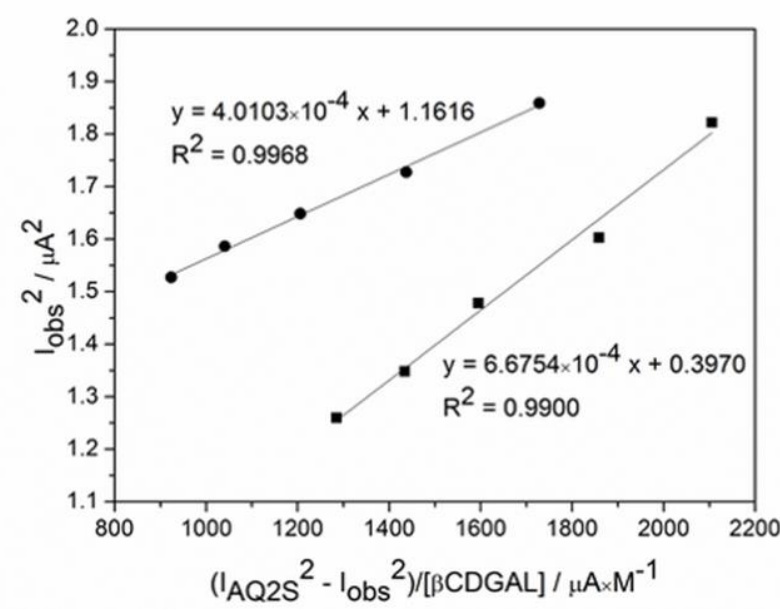

(b)

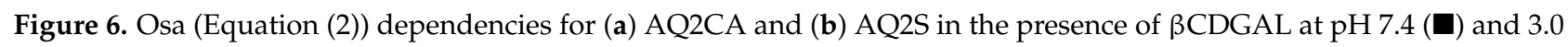
$(\bullet)$. Reduction peak currents were recorded using cyclic voltammetry at a scan rate of $100 \mathrm{mV} \cdot \mathrm{s}^{-1}$.

Table 2. Association constants of AQ2CA and AQ2S complexes with $\beta$-cyclodextrin and its derivatives in Britton-Robinson buffer at $\mathrm{pH} 7.4$ and 3.0.

\begin{tabular}{|c|c|c|}
\hline \multirow{2}{*}{ Complex } & \multicolumn{2}{|c|}{ Association constant $K_{1: 1}\left(M^{-1}\right)$} \\
\hline & pH 7.4 & pH 3.0 \\
\hline$A Q 2 C A-\beta C D$ & $315 \pm 40$ & $1360 \pm 180$ \\
\hline AQ2CA- $\beta C$ Damine & $800 \pm 70$ & $2860 \pm 190$ \\
\hline AQ2CA- $\beta C D L i p$ & $935 \pm 60$ & $2680 \pm 230$ \\
\hline AQ2CA- $\beta C D G A L$ & $1250 \pm 90$ & $2700 \pm 150$ \\
\hline AQ2S- $\beta C D$ & $175 \pm 30$ & $840 \pm 50$ \\
\hline AQ2S- $\beta C$ Damine & $250 \pm 45$ & $3040 \pm 190$ \\
\hline AQ2S- $\beta$ CDLip & $910 \pm 40$ & $2085 \pm 135$ \\
\hline AQ2S- $\beta C D G A L$ & $1450 \pm 60$ & $2500 \pm 120$ \\
\hline
\end{tabular}


The values of the association constants of the AQ2CA-cyclodextrin complexes obtained using the cyclic voltammetry method were consistent with those obtained by UV-Vis spectroscopy. Moreover, both AQ2CA and AQ2S formed more stable complexes with the modified $\beta C D$ s than with the native $\beta C D$, and the largest association constants were also obtained at $\mathrm{pH} 7.4$ with $\beta$ CDGAL. As mentioned above, strong proton-acceptor $\pi-\pi$ interactions between the triazole ring of the cyclodextrin side group and the aromatic ring of the drug molecule was responsible for the increased association constants of the complexes. The association constants also depended on $\mathrm{pH}$ for $\mathrm{AQ} 2 \mathrm{~S}$, and the weaker binding at $\mathrm{pH} 7.4$ can be understood in terms of the lower affinity of the charged form of this drug for the hydrophobic CD cavity. The formation of strong inclusion complexes would increase solubility, thus, facilitating the delivery of the AQ2S and AQ2CA drugs and preventing the encapsulated drug from generating reactive oxygen species.

\subsection{Determination of the Association Constants of Daunorubicin-Cyclodextrin Inclusion Complexes at $\mathrm{pH}$ 7.4. and 5.5}

Due to the fact that a cancer cell environment is more acidic ( $\mathrm{pH} 5.5)$ than that of healthy cells ( $\mathrm{pH} 7.4$ ), the carrier should be $\mathrm{pH}$ sensitive to enable the release of the DNR drug. The $\beta C D$ s with triazole in the side chain were, therefore, chosen to compare the association constants of DNR-cyclodextrin complexes at these two values of $\mathrm{pH}$. The same Osa (Equation (2)) dependencies were used to follow the changes in DNR reduction current in the absence and presence of the CDs. The Osa dependencies of $\mathrm{I}^{2}{ }_{\text {obs }}$ vs. $\left(\mathrm{I}^{2} \mathrm{DNR}-\mathrm{I}^{2}{ }_{\text {obs }}\right) /[\beta C D G A L]$ for the two selected $\mathrm{pH}$ values are shown in Figure 7.

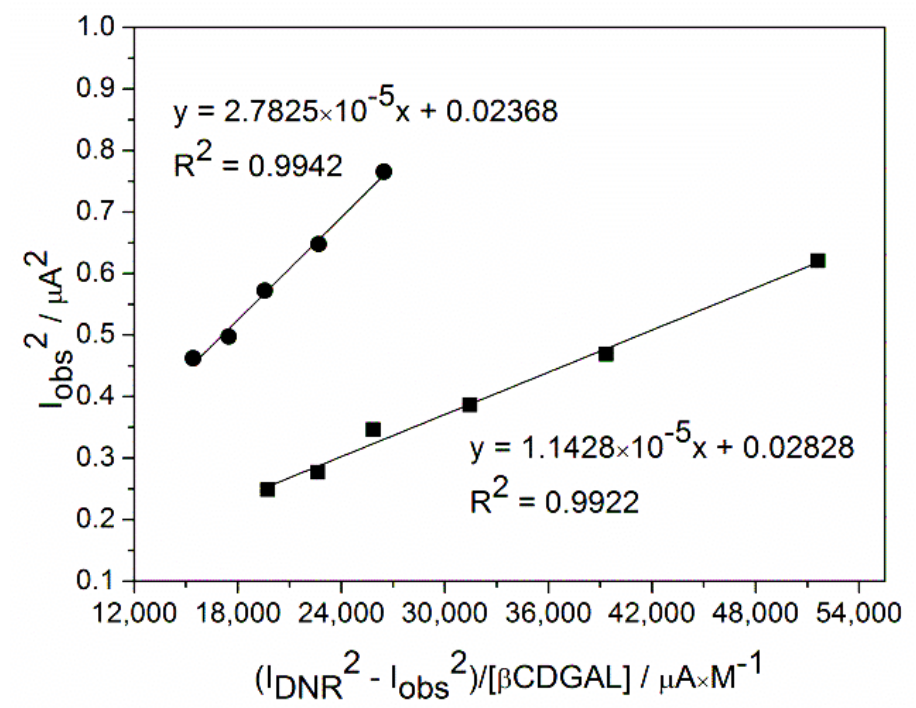

Figure 7. Osa (Equation (2)) dependencies for DNR in the presence of $\beta C D G A L$ at pH 7.4 (ם) and pH $5.5(\bullet)$.

The values in Table 3 show that modification of cyclodextrin with a triazole linker increased the association constants of DNR-CD complexes, as seen in the case of AQ2CA and AQ2S. Exploiting the additional interaction between the drug aromatic ring and the triazole linker of cyclodextrin is, therefore, a general method of increasing the stability of the complexes. DNR- $\beta C D$ derivatives were also sensitive to the $\mathrm{pH}$ change from 5.5 to 7.4. 
Table 3. Association constants of DNR complexes with $\beta$-cyclodextrin and its derivatives in BrittonRobinson buffer at $\mathrm{pH} 7.4$ and 5.5.

\begin{tabular}{ccc}
\hline \multirow{2}{*}{ Complex } & \multicolumn{2}{c}{ Association Constant $\mathbf{K}_{\mathbf{1 : 1}} \mathbf{( M}^{\mathbf{- 1}} \mathbf{)}$} \\
\cline { 2 - 3 } & $\mathbf{p H ~ 7 . 4}$ & $\mathbf{p H ~ 5 . 5}$ \\
\hline DNR- $\beta C D$ & $970 \pm 35$ & $780 \pm 30$ \\
\hline DNR- $\beta$ CDTriazol & $11,000 \pm 500$ & $3000 \pm 200$ \\
\hline DNR- $\beta$ CDGAL & $84,000 \pm 5500$ & $37,200 \pm 3200$ \\
\hline
\end{tabular}

Interestingly, the situation was different in the case of $A Q 2 C A$ and $A Q 2 S$ compared to DNR. At a $\mathrm{pH}$ of 5.5, which is characteristic of a cancer cell environment, these cyclodextrins formed weaker complexes with DNR than at a physiological $\mathrm{pH}$ (pH 7.4). Smaller values of stability at a lower $\mathrm{pH}$ (5.5) can be explained by the fact that DNR is in its cationic form at this $\mathrm{pH}$, since the $\mathrm{pKa}$ value for DNR is 7.48 [35]. At a higher $\mathrm{pH}$, the fraction of the deprotonated (i.e., neutral) form of the drug is larger; hence, its binding to the hydrophobic cavity increases. Thus, the difference in the charges of the anthraquinone drugs DNR and AQ2CA (at acidic $\mathrm{pH}, \mathrm{DNR}$ is positively charged, while AQ2CA is negatively charged) is the reason for the different properties of their complexes at acidic and neutral $\mathrm{pH}$. It may be noted that, at $\mathrm{pH} 5.5$, the proton-acceptor $\pi-\pi$ interactions should be additionally weakened due to the interaction of protons with lone electron pairs present on the nitrogen atoms of the triazole linker.

Significantly high values of the association constants of DNR inclusion complexes with $\beta C D G A L$ at both $\mathrm{pH}$ values confirmed the affinity of drug molecules for the cyclodextrin cavity. Moreover, the higher stability of the complex at a physiological $\mathrm{pH}$ than at a $\mathrm{pH}$ of 5.5 is promising in view of cancer therapies. At a higher $\mathrm{pH}$, the carrier strongly encapsulates DNR, protecting it from oxygen-radical formation reactions, while, at a lower $\mathrm{pH}$, corresponding to the cancer environment, the release of the drug from the complex becomes favorable.

Lower values of the association constants of anthracycline complexes with $\beta C D$ Triazole as compared with $\beta C D G A L$ may indicate some contribution of the self-inclusion complex between the side substituents of the $\beta C D$ Triazole derivative and the cavity of this cyclodextrin.

\subsection{Determination of the $\beta C D$ Complexes Binding Site by Nuclear Magnetic Spectroscopy}

The structures of the complexes of $\beta C D$ and anthraquinone-derived drugs were investigated by nuclear Overhauser effect spectroscopy (NOESY). The representative ${ }^{1} \mathrm{H}$ NOESY spectrum for the $\beta C D G A L / A Q 2 S$ system is shown in Figure 8 . The ${ }^{1} \mathrm{H}$ NMR signals of $\beta C D G A L$ assigned to the protons inside the cyclodextrin cavity are located at 4.9-5.3 ppm. These signals have cross-peaks with the signals of aromatic protons of AQ2S (7.8-8.5 ppm), which shows that AQ2S is placed inside of $\beta C D G A L$. The reference ${ }^{1} \mathrm{H}$ NOESY spectrum of a sample containing only AQ2S shows that the cross-peaks at $8.1 \mathrm{ppm}$ placed vertically should be attributed to the internal interactions within the AQ2S ligand. Therefore, the lack of four vertical cross-peaks in the case of the external protons of $\beta C D G A L$, i.e., not resolved multiplets at $\sim 3.6 \mathrm{ppm}$ and $\sim 5 \mathrm{ppm}$, excludes the binding site of AQ2S on the external surface of $\beta C D G A L$. Analogous results were obtained for the AQ2CA/ $\beta C D G A L$ system (see the supporting information for further details, Figures S1-S15). 


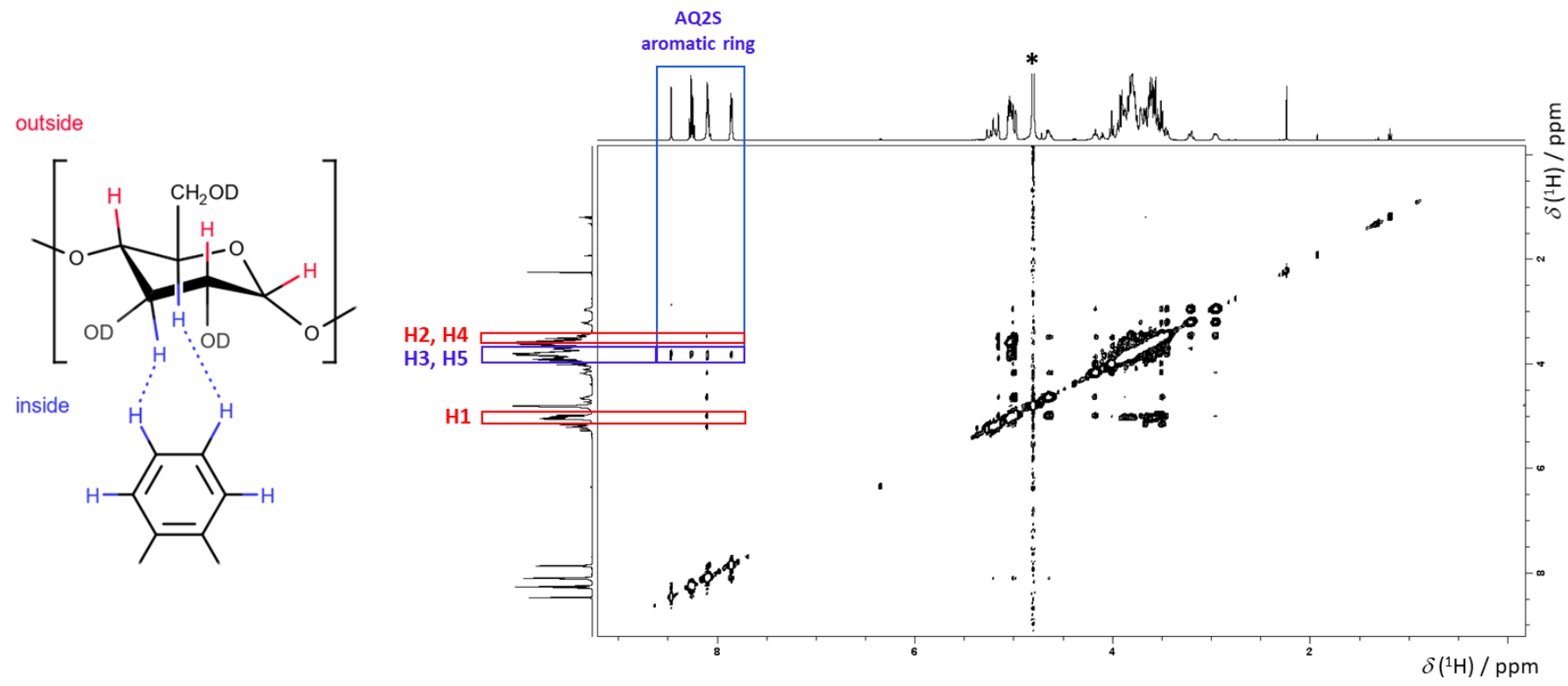

Figure 8. ${ }^{1} \mathrm{H}$ NOESY spectrum of the $\beta C D G A L / A Q 2 S$ system. The cross-peaks between the H3 and $\mathrm{H} 5$ internal protons of $\beta C D G A L$ and the protons in the aromatic rings of AQ2S are marked by the blue rectangle. In this spectrum, there is a lack of evidence for interactions between the external protons of $\beta C D G A L$, i.e., $\mathrm{H} 1, \mathrm{H} 2$, and $\mathrm{H} 4$, and protons of the ligand, AQ2S (red rectangles, no signals present). The signal of HDO is marked by an asterisk.

\section{Material and Methods}

\subsection{Chemicals and Reagents}

All reagents were of high purity ( $\geq 97 \%$ ). Anthraquinone-2-carboxylic acid (AQ2CA) and anthraquinone-2-sulfonic sodium salt (AQ2S) were purchased from Sigma-Aldrich (Steinheim, Germany) and used without further purification. Daunorubicin (DNR) hydrochloride salt was purchased from AK Scientific (Union City, CA, USA). $\beta$-Cyclodextrin $(\beta C D)$ and 6-monodeoxy-6-monoamino- $\beta$-cyclodextrin hydrochloride ( $\beta C D a m i n e)$ were obtained from Sigma-Aldrich. The synthesis of the lipoic acid ( $\beta$ CDLip) [29], triazole ( $\beta C D$ Triazole), and galactosamine ( $\beta C D G A L)$ derivatives of $\beta$-cyclodextrin [30] was performed as previously described. Other compounds were purchased from Sigma-Aldrich. Buffers were prepared using water from a Milli-Q ultrapure water system. The BrittonRobinson buffers ( $\mathrm{pH} 7.4,5.5$, and 3.0) were prepared in the usual way via the addition of appropriate amounts of $0.2 \mathrm{M}$ sodium hydroxide to a $0.04 \mathrm{M}$ solution of orthophosphoric acid, acetic acid, and boric acid. The $\mathrm{pH}$ was controlled using a pH Meter E2 (Mettler Toledo). The ionic strength of the buffer was adjusted to $0.5 \mathrm{M}$ with potassium chloride. All experiments were carried out at room temperature $\left(25 \pm 1^{\circ} \mathrm{C}\right)$.

\subsection{UV-Vis Spectroscopy}

The UV-Vis measurements were performed using an Agilent Technologies Cary 60 UVVis Spectrophotometer (Santa Clara, CA, USA). All UV-Vis spectra were measured using quartz cuvettes with a $1 \mathrm{~cm}$ optical path length. For pKa determination the $0.2 \mathrm{mg} / \mathrm{mL}$ concentration of $\beta C D$ Triazole, $\beta C D G A L$ or $\beta C D L i p$ in Britton-Robinson buffer were used.

\subsection{Voltammetry}

The cyclic (CV) and square-wave (SWV) voltammetry measurements were carried out using an EC Epsilon potentiostat (BASI). The electrochemical cell was kept in a Faraday cage. All electrochemical experiments were performed using a three-electrode arrangement with a glassy carbon electrode (BASi, $3 \mathrm{~mm}$ diameter) as the working electrode, a platinum foil as the counter electrode, and a silver/silver chloride $(\mathrm{Ag} / \mathrm{AgCl})$ electrode $(\mathrm{BASi})$ in a saturated solution of $\mathrm{KCl}$ as the reference electrode. Before each electrochemical experiment, 
the surface of the glassy carbon electrode was polished using $0.05 \mu \mathrm{m}$ alumina powder on a Buehler polishing cloth. After polishing, to remove traces of alumina from the electrode surface, the working electrode was rinsed with copious amounts of Milli-Q ultrapure water (resistivity $18.2 \mathrm{M} \Omega \cdot \mathrm{cm}$ ).

\subsection{Phase Solubility Diagrams}

Solubility studies of anthraquinone-2-carboxylic acid with three different cyclodextrins were carried out according to the Higuchi and Connors procedure [33]. The solutions of cyclodextrin in water and Britton-Robinson buffers ( $\mathrm{pH} 7.4$ and 5.5) were prepared in a concentration range of $0-3 \mathrm{mM}$. A constant amount of AQ2CA ( $3 \mathrm{mM})$ that exceeded its solubility was added into the cyclodextrin solution. Molar ratios of AQ2CA/CD were 1:0, 1:0.2, 1:0.4, 1:0.6, 1:0.8, and 1:1. Three samples of each molar ratio were prepared. The suspensions were shaken for $24 \mathrm{~h}$ at $25^{\circ} \mathrm{C}$, after which equilibrium was reached. After $24 \mathrm{~h}$, the concentration of the dissolved drug was monitored by UV-Vis spectroscopy and plateaued; thus, the maximum dissolved drug was achieved. Subsequently, the samples were filtered using a $0.45 \mu \mathrm{m}$ filter and appropriately diluted. The aliquots of solutions were assayed for AQ2CA again, by UV-Vis spectroscopy, in the 200-600 nm range with a maximum absorbance value for AQ2CA at $335 \mathrm{~nm}$. The apparent association constant $\left(\mathrm{K}_{1: 1}\right)$ for the complexes formed was calculated from the slope of the phase solubility diagram and the solubility of AQ2CA in water, Britton-Robinson buffer at $\mathrm{pH} 7.4$, and Britton-Robinson buffer at $\mathrm{pH} 3.0$, at $25^{\circ} \mathrm{C}$. The association constants of the inclusion complexes were determined using the following equation:

$$
\mathrm{K}_{1: 1}=\frac{\text { Slope }}{\mathrm{S}_{0}(1-\text { Slope })}
$$

where $\mathrm{K}_{1: 1}$ is the association constant and $\mathrm{S}_{0}$ is the solubility of AQ2CA in the absence of cyclodextrin. The slope was measured by UV-Vis spectroscopy from the initial straightline part of the AQ2CA concentration vs. CD concentration plot. The uncertainty was determined as the standard deviation of the three values of the association constants obtained from three different repetitions of the given system.

\subsection{NMR Measurements}

${ }^{1} \mathrm{H}$ NOESY NMR spectra were acquired using an AVANCE III Bruker $500 \mathrm{MHz}$ spectrometer equipped with a cryoprobe at the magnetic field strength of $11.75 \mathrm{~T}$ and room temperature (298 K). The recorded NOESY spectra have a high signal-to-noise ratio. We did not notice any significant loss of the signal-to-noise ratio due to the possible unfavorable tumbling rate estimated from the molecular weight of the studied cyclodextrin derivatives. See also [36] for a broaden discussion of NMR pulse sequences utilizing the Overhauser effect. The recorded NMR signals of cyclodextrin were assigned to ${ }^{1} \mathrm{H}$ nuclei based on the data reported in $[30,37]$. The samples were prepared by dissolution of an equimolar mixture of $\beta C D G A L$ and a derivative of anthraquinone (AQ2S, $A Q 2 C A$, and DNR) in deuterium-enriched water $(99.5 \% \mathrm{D}$, Sigma-Aldrich). The obtained concentrations of saturated solutions of $\beta C D G A L$ complexes varied in the range from 1 (DNR) to $10 \mathrm{mM}$ (AQ2S and AQ2CA). The ${ }^{1} \mathrm{H}$ NMR chemical shifts were referenced to the residual signal of HDO (4.79 ppm).

3.6. Evaluation of the Association Constants of Drug-Cyclodextrin Inclusion Complexes by Cyclic and Square-Wave Voltammetry

For the cyclic voltammetry experiments, the concentration of AQ2CA and AQ2S was $2.5 \times 10^{-5} \mathrm{M}$, whereas the concentrations of $\beta C D, \beta C$ Damine, $\beta$ CDLip, and $\beta C D G A L$ varied from $2.5 \times 10^{-4}$ to $1.08 \times 10^{-3} \mathrm{M}$. Cyclic voltammetry $(\mathrm{CV})$ was carried out at a scan rate of $100 \mathrm{mV} \cdot \mathrm{s}^{-1}$. For the SWV measurements, the concentration of DNR was $1.0 \times 10^{-6} \mathrm{M}$, while the concentrations of $\beta C D, \beta C D$ Triazol, and $\beta C D G A L$ were increased in the range from $1.0 \times 10^{-5}$ to $6.7 \times 10^{-5} \mathrm{M}$. Before each SWV run, the electrode was 
electrochemically cleaned by applying a negative potential $(-1.0 \mathrm{~V})$ for $40 \mathrm{~s}$, as described by Mora et al. [38]. The potential was varied between $-0.2 \mathrm{~V}$ and $-0.9 \mathrm{~V}$ at a frequency of $25 \mathrm{~Hz}$, with an amplitude of $25 \mathrm{mV}$ and a step size of $2 \mathrm{mV}$. Prior to all electrochemical measurements, the buffer solutions were purged with purified argon for $15 \mathrm{~min}$.

$\mathrm{AQ} 2 \mathrm{CA}, \mathrm{AQ2S}$, and DNR are electroactive compounds. As a result of the potential change, they undergo reduction and oxidation reactions involving two electrons and two protons (Scheme 1).

A<smiles>[R]c1ccc2c(c1)C(=O)c1ccccc1C2=O</smiles>

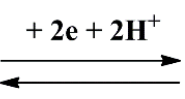<smiles>[R]c1ccc2c(c1)C(O)c1ccccc1C2O</smiles>

AQ2CA: $\quad \mathrm{R}-\mathrm{COOH}$

AQ2S:

$\mathrm{R}-\mathrm{SO}_{3} \mathrm{Na}$

B<smiles>COc1cccc2c1C(=O)c1c(O)c3c(c(O)c1C2=O)C[C@@](O)(C(C)=O)C[C@@H]3OC1C[C@@H](N)[C@H](C)O1</smiles>

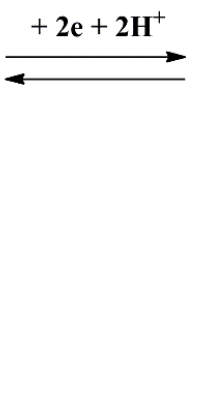

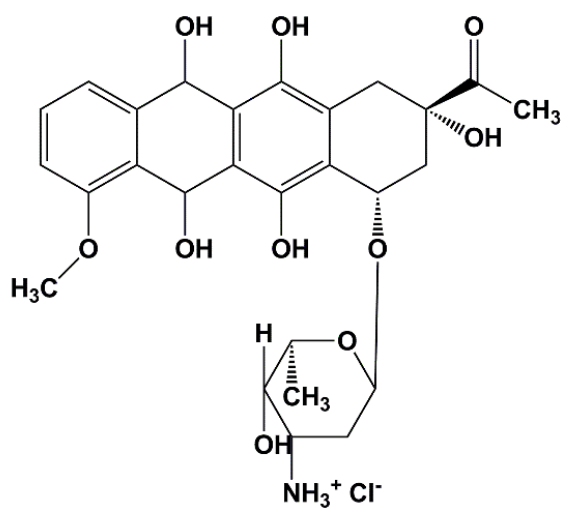

Scheme 1. Oxidation and reduction reactions of: (A) AQ2CA and AQ2S; (B) DNR.

Cyclic and square-wave voltammetry reduction peak currents were employed for the calculation of the drug-cyclodextrin complex formation constants based on the Osa equation [39]:

$$
\mathrm{I}_{\text {obs }}^{2}=\frac{\left(\mathrm{I}_{\text {drug }}^{2}-\mathrm{I}_{\text {obs }}^{2}\right)}{\mathrm{K}_{1: 1} \cdot[\mathrm{CD}]}+\mathrm{I}_{\text {drug: } \mathrm{CD}}^{2}
$$

where $\mathrm{I}_{\mathrm{obs}}$ is the observed reduction peak current of the quinone group of the drug; $\mathrm{I}_{\mathrm{drug}}$ and $\mathrm{I}_{\mathrm{drug}: \mathrm{CD}}$ are the reduction peak currents for the free drug and inclusion complex, respectively; $K_{1: 1}$ is the complex formation constant; and [CD] is the concentration of cyclodextrin. The value of $\mathrm{K}_{1: 1}$ was calculated from the slope of the linear plot of $\mathrm{I}_{\mathrm{obs}}{ }^{2} \mathrm{vs}$. $\left(\mathrm{I}_{\mathrm{drug}}{ }^{2}-\mathrm{I}_{\mathrm{obs}}{ }^{2}\right) /[\mathrm{CD}]$.

\section{Conclusions}

$\beta$-Cyclodextrin derivatives containing an aromatic triazole ring as the side group were demonstrated to be suitable carriers of drugs which contain an anthraquinone moiety. The spectroscopic and voltammetry measurements showed that AQ2CA and AQ2S form stable water inclusion complexes with cyclodextrin with 1:1 stoichiometries. The phase solubility diagrams for the AQ2CA-cyclodextrin inclusion complexes were classified as $A_{L}$ type. The advantage of using the designed cyclodextrins to complex the drugs lies in the increased 
solubility of these poorly soluble drugs, allowing the delivery of larger doses of the drugs when encapsulated in the CD carriers. $\beta C D$ Lip and $\beta C D G A L$ derivatives formed stronger inclusion complexes with $\mathrm{AQ} 2 \mathrm{CA}$ and $\mathrm{AQ} 2 \mathrm{~S}$ than with native $\beta C D$, due to the aromatic triazole linker, which was involved in direct $\pi-\pi$ interactions with these drugs. The AQ2CA and AQ2S drugs are anionic in neutral medium, whereas they are protonated at a low $\mathrm{pH}$ (i.e., neutral). This led to the observed sensitivity of their $\mathrm{CD}$ complexes to changes in $\mathrm{pH}$. At a $\mathrm{pH}$ of 3.0 (characteristic of gastric juices), the association constants of complexes with the neutral form of the drug were much larger than those at a physiological $\mathrm{pH}(7.4)$, when the drugs were in their anionic form and showed a lower affinity for the hydrophobic cyclodextrin cavity. In addition, cyclodextrin derivatives containing a triazole linker are protonated at a $\mathrm{pH}$ below 4.5, which may result in stronger binding of the anionic drugs. This is important in view of the potential medical applications of these drugs complexed with $\beta C D L i p$ and $\beta C D G A L$ derivatives.

$\beta C D$ Triazole and $\beta C D G A L$ derivatives also formed stronger inclusion complexes with anthracyclines as compared with native $\beta C D$, as shown for the example of DNR. Interestingly, stronger inclusion complexes with DNR were, however, formed at a higher $\mathrm{pH}(7.4)$ than at a more acidic $\mathrm{pH}$, in contrast to AQ2CA. This was due to the positive charge of DNR at a lower $\mathrm{pH}$, which was less prone to form inclusion complexes with the modified CDs. Such behavior is therapeutically promising since, at a higher $\mathrm{pH}$, which corresponds to the physiological pH of normal cells, some of the drug molecules would be in their neutral form strongly bound to cyclodextrin. Accordingly, they would not be released from the carrier, and therefore would not undergo negative side reactions. At $\mathrm{pH}$ 5.5, characteristic for the cancer cell environment, the positively charged drug would be released from the carrier, becoming free to intercalate into the DNA helices of the cancer cell.

It can be concluded that cyclodextrins modified with an aromatic triazole ring, especially $\beta C D G A L$, are promising carriers of drugs containing an anthraquinone moiety. The formation of $\mathrm{CD}$ complexes with the anthraquinone group improves the solubility of the drug and, more importantly, can protect the drug from unwanted side reactions, such as the generation of reactive oxygen species, which impede the application of these highly effective drugs.

Supplementary Materials: The following are available online, Reactive oxygen species (ROS) production in the presence of NADH, Scheme S1. Reactive oxygen species (ROS) production in the presence of NADH. Table S1. NMR spectra of $\beta-C D$ complexes given in the supporting material, Figure S1. 1H NMR spectrum of $\beta$-cyclodextrin functionalized by galactosamine ( $\beta$-CDGAL) dissolved in D2O. The residual solvent peak at $\delta\left({ }^{1} \mathrm{H}\right)=4.79 \mathrm{ppm}$ is marked by an asterisk, Figure S2. $1 \mathrm{H}$ NOESY spectrum of $\beta$-CDGAL dissolved in D2O, Figure S3. The spectral region of the $1 \mathrm{H}$ NOESY spectrum given in Figure S2 showing the interaction between AQ2S and $\beta$-CDGAL, Figure S4. 1H NMR spectrum of antraquinone-2-sulfonic acid (AQ2S) dissolved in D2O. The residual solvent peak at $\delta\left({ }^{1} \mathrm{H}\right)=4.79 \mathrm{ppm}$ is marked by an asterisk, Figure S5. $1 \mathrm{H}$ NMR spectrum of an equimolar mixtrure of AQ2S and $\beta$-CDGAL dissolved in D2O. The residual solvent peak at $\delta\left({ }^{1} \mathrm{H}\right)=4.79 \mathrm{ppm}$ is marked by an asterisk, Figure S6. 1H NOESY spectrum of an equimolar mixtrure of AQ2S and $\beta$-CDGAL dissolved in D2O, Figure S7. The spectral region of the $1 \mathrm{H}$ NOESY spectrum given in Figure S6 showing the interaction between AQ2S and $\beta$-CDGAL, Figure S8. 1H NMR spectrum of antraquinone-2-carboxylic acid (AQ2CA) dissolved in DMSO-d6. The residual solvent peak at $\delta\left({ }^{1} \mathrm{H}\right)=2.50 \mathrm{ppm}$ is marked by an asterisk, Figure S9. $1 \mathrm{H}$ NMR spectrum of an equimolar mixtrure of AQ2CA and $\beta$-CDGAL dissolved in D2O. The residual solvent peak at $\delta\left({ }^{1} \mathrm{H}\right)=4.79 \mathrm{ppm}$ is marked by an asterisk, Figure S10. 1H NOESY spectrum of an equimolar mixtrure of AQ2CA and $\beta$-CDGAL dissolved in D2O, Figure S11. The spectral region of the 1H NOESY spectrum given in Figure S10 showing the interaction between $A Q 2 S$ and $\beta$-CDGAL, Figure S12. $1 \mathrm{H}$ NMR spectrum of daunorubicin (DNR) dissolved in D2O. The residual solvent peak at $\delta\left({ }^{1} \mathrm{H}\right)=4.79 \mathrm{ppm}$ is marked by an asterisk, Figure S13. 1H NOESY spectrum of DNR dissolved in D2O, Figure S14. 1H NMR spectrum of an equimolar mixtrure of DNR and $\beta$-CDGAL dissolved in D2O. The residual solvent 
peak at $\delta\left({ }^{1} \mathrm{H}\right)=4.79 \mathrm{ppm}$ is marked by an asterisk, Figure S15. 1H NOESY spectrum of an equimolar mixtrure of DNR and $\beta$-CDGAL dissolved in D2O.

Author Contributions: Conceptualization, O.S. and R.B.; investigation, A.K. and M.M.; data curation, A.K. and O.S.; conducting NMR experiments and NMR data collection, P.G. (Piotr Garbacz) and P.G. (Paulina Gwardys); writing-original draft preparation, A.K., O.S. and R.B.; writing-review and editing, O.S. and R.B.; supervision, R.B.; funding acquisition, R.B. All authors have read and agreed to the published version of the manuscript.

Funding: This work was financially supported by the Polish National Science Center (project no. 2018/31/B/ST4/00406). The study was partly carried out at the Biological and Chemical Research Center, the University of Warsaw, established within a project co-financed by the European Union from the European Regional Development Fund under the Operational Program Innovative Economy, 2007-2013.

Institutional Review Board Statement: Not applicable.

Informed Consent Statement: Not applicable.

Data Availability Statement: Not applicable.

Conflicts of Interest: The authors declare no conflict of interest.

Sample Availability: Samples of the compounds are not available from authors.

\section{References}

1. Greidanus, J.; Willemse, P.H.; Uges, D.R.; Oremus, E.T.; De Langen, Z.J.; De Vries, E.G. Continuous infusion of low-dose doxorubicin, epirubicin and mitoxantrone in cancer chemotherapy: A review. Pharm. Weekbl. 1988, 10, 237-245. [CrossRef]

2. Patterson, L.H. Bioreductively activated antitumor N-oxides: The case of AQ4N, a unique approach to hypoxia-activated cancer chemotherapy. Drug Metab. Rev. 2002, 34, 581-592. [CrossRef]

3. Andersen, D.O.; Weber, N.D.; Wood, S.G.; Hughes, B.G.; Murray, B.K.; North, J.A. In vitro virucidal activity of selected anthraquinones and anthraquinone derivatives. Antivir. Res. 1991, 16, 185-196. [CrossRef]

4. Panigrahi, G.K.; Yadav, A.; Mandal, P.; Tripathi, A.; Das, M. Immunomodulatory potential of Rhein, an anthraquinone moiety of Cassia occidentalis seeds. Toxicol. Lett. 2016, 245, 15-23. [CrossRef] [PubMed]

5. Kshirsagar, A.D.; Panchal, P.V.; Harle, U.N.; Nanda, R.K.; Shaikh, H.M. Anti-inflammatory and antiarthritic activity of anthraquinone derivatives in rodents. Int. J. Inflamm. 2014, 2014, 690596. [CrossRef]

6. Khanal, P.; Patil, B.M.; Chand, J.; Naaz, Y. Anthraquinone Derivatives as an Immune Booster and their Therapeutic Option Against COVID-19. Nat. Prod. Bioprospect. 2020, 10, 325-335. [CrossRef]

7. Mazouria, S.E.; Aanniza, T.; Touhtouha, J.; Kandoussia, I.; Hakmia, M.; Belyamanib, L.; Ibrahimia, A.; Ouadghiria, M. Anthraquinones: A Promising Multi-target Therapeutic Scaffold To Treat COVID-19. Int. J. Appl. Biol. Pharm. 2021, 12, 338-355.

8. Wald, A. Is chronic use of stimulant laxatives harmful to the colon? J. Clin. Gastroenterol. 2003, 36, 386-389. [CrossRef] [PubMed]

9. Kumar, A.; Katiyar, S.B.; Agarwal, A.; Chauhan, P.M. Perspective in antimalarial chemotherapy. Curr. Med. Chem. 2003, 10, 1137-1150. [CrossRef]

10. Winter, R.W.; Cornell, K.A.; Johnson, L.L.; Ignatushchenko, M.; Hinrichs, D.J.; Riscoe, M.K. Potentiation of the antimalarial agent rufigallol. Antimicrob. Agents Chemother. 1996, 40, 1408-1411. [CrossRef] [PubMed]

11. Martinelli, V.; Radaelli, M.; Straffi, L.; Rodegher, M.; Comi, G. Mitoxantrone: Benefits and risks in multiple sclerosis patients. Neurol. Sci. 2009, 30, 167-170. [CrossRef]

12. Pickhardt, M.; Gazova, Z.; von Bergen, M.; Khlistunova, I.; Wang, Y.; Hascher, A.; Biernat, J.; Mandelkow, E. Anthraquinones inhibit tau aggregation and dissolve Alzheimer's paired helical filaments in vitro and in cells. J. Biol. Chem. 2005, 280, 3628-3635. [CrossRef] [PubMed]

13. Liu, T.; Jin, H.; Sun, Q.R.; Xu, J.H.; Hu, H.T. Neuroprotective effects of emodin in rat cortical neurons against beta-amyloid-induced neurotoxicity. Brain Res. 2010, 1347, 149-160. [CrossRef] [PubMed]

14. Liu, T.; Hu, H.T.; Sun, Q.R. Neuroprotective effects of emodin on primary rat cortical neurons apoptosis induced by hydrogen peroxide. J. Chin. Med. Mater. 2010, 33, 1116-1119.

15. Wang, C.; Zhang, D.; Ma, H.; Liu, J. Neuroprotective effects of emodin-8-O-beta-D-glucoside in vivo and in vitro. Eur. J. Pharmacol. 2007, 577, 58-63. [CrossRef]

16. Jackson, T.C.; Verrier, J.D.; Kochanek, P.M. Anthraquinone-2-sulfonic acid (AQ2S) is a novel neurotherapeutic agent. Cell Death Dis. 2013, 4, e451. [CrossRef] [PubMed]

17. Park, J.G.; Kim, S.C.; Kim, Y.H.; Yang, W.S.; Kim, Y.; Hong, S.; Kim, K.H.; Yoo, B.C.; Kim, S.H.; Kim, J.H.; et al. Anti-Inflammatory and Antinociceptive Activities of Anthraquinone-2-Carboxylic Acid. Mediat. Inflamm. 2016, 2016, 1903849. [CrossRef] [PubMed] 
18. Megías-Vericat, J.E.; Martínez-Cuadrón, D.; Sanz, M.Á.; Poveda, J.L.; Montesinos, P. Daunorubicin and cytarabine for certain types of poor-prognosis acute myeloid leukemia: A systematic literature review. Expert Rev. Clin. Pharmacol. 2019, 12, 197-218. [CrossRef]

19. Antolín, S.; Acea, B.; Albaina, L.; Concha, Á.; Santiago, P.; García-Caballero, T.; Mosquera, J.J.; Varela, J.R.; Soler, R.; Calvo, L. Primary systemic therapy in HER2-positive operable breast cancer using trastuzumab and chemotherapy: Efficacy data, cardiotoxicity and long-term follow-up in 142 patients diagnosed from 2005 to 2016 at a single institution. Breast Cancer 2019, 11, 29-42. [CrossRef]

20. Meyer, M.; Seetharam, M. First-Line Therapy for Metastatic Soft Tissue Sarcoma. Curr. Treat. Options Oncol. 2019, 20, 6. [CrossRef]

21. Chen, W.; Liu, I.; Tomiyasu, H.; Lee, J.; Cheng, C.; Liao, A.T.; Liu, B.; Liu, C.; Lin, C. Imatinib enhances the anti-tumour effect of doxorubicin in canine B-cell lymphoma cell line. Vet. J. 2019, 254, 105398. [CrossRef] [PubMed]

22. Shukla, V.; Asthana, S.; Gupta, P.; Dwivedi, P.D.; Tripathi, A.; Das, M. Toxicity of Naturally Occurring Anthraquinone. In Advances in Molecular Toxicology; Elsevier: Amsterdam, The Netherlands, 2017; Volume 11, pp. 1-50.

23. Barbosa, R.R.; Bourguignon, T.B.; Torres, L.D.; Arruda, L.S.; Jacques, T.M.; Serpa, R.G.; Calil, O.A.; Barbosa, L.F.M. Anthracyclineassociated cardiotoxicity in adults: Systematic review on the cardioprotective role of beta-blockers. Rev. Assoc. Med. Bras. 2018, 64, 745-754. [CrossRef]

24. Volkova, M.; Raymond, R., 3rd. Anthracycline cardiotoxicity: Prevalence, pathogenesis and treatment. Curr. Cardiol. Rev. 2011, 7, 214-220. [CrossRef]

25. Mao, M.; Ruan, W.; Chen, Q. Understanding the Aqueous Solubility of Anthraquinone Sulfonate Salts: The Quest for High Capacity Electrolytes of Redox Flow Batteries. J. Electrochem. Soc. 2020, 167, 070522. [CrossRef]

26. Fink, C.; Sun, D.; Wagner, K.; Schneider, M.; Bauer, H.; Dolgos, H.; Mäder, K.; Peters, S.A. Evaluating the Role of Solubility in Oral Absorption of Poorly Water-Soluble Drugs Using Physiologically-Based Pharmacokinetic Modeling. Clin. Pharmacol. Ther. 2020, 107, 650-661. [CrossRef] [PubMed]

27. Swiech, O.; Opuchlik, L.J.; Wojciuk, G.; Stepkowski, T.; Kruszewski, M.; Bilewicz, R. Doxorubicin carriers based on Au nanoparticles-Effect of shape and gold-drug linker on the carrier toxicity and therapeutic performance. RSC Adv. 2016, 6, 31960-31967. [CrossRef]

28. Dzwonek, M.; Załubiniak, D.; Piątek, P.; Cichowicz, G.; Męczynska-Wielgosz, S.; Stępkowski, T.; Kruszewski, M.; Więckowska, A.; Bilewicz, R. Towards potent but less toxic nanopharmaceuticals-Lipoic acid bioconjugates of ultrasmall gold nanoparticles with an anticancer drug and addressing unit. RSC Adv. 2018, 8, 14947-14957. [CrossRef]

29. Swiech, O.; Majdecki, M.; Debinski, A.; Krzak, A.; Bilewicz, R. Competition between self-inclusion and drug binding explains the $\mathrm{pH}$ dependence of the cyclodextrin drug carrier-Molecular modelling and electrochemistry studies. Nanoscale 2016, 8, 16733-16742. [CrossRef] [PubMed]

30. Swiech, O.; Krzak, A.; Majdecki, M.; Trębińska-Stryjewska, A.; Wakuła, M.; Garbacz, P.; Gasiorowska, W.; Bilewicz, R. Watersoluble galactosamine derivative of $\beta$-cyclodextrin as protective ligand and targeted carrier for delivery of toxic anthracycline drug. Int. J. Pharm. 2020, 589, 119834. [CrossRef]

31. Krzak, A.; Bilewicz, R. Voltammetric/UV-Vis study of temozolomide inclusion complexes with cyclodextrin derivatives. Bioelectrochemistry 2020, 136, 107587-107593. [CrossRef] [PubMed]

32. Takahashi, K.; Andou, K.; Fujiwara, S. Characterization and structural determination of 3A-amino-3A-deoxy-(2AS, 3AS)cyclodextrins by NMR spectroscopy. Polym. J. 2012, 44, 850-854. [CrossRef]

33. Higuchi, T.; Connors, K.A. Phase-solubility techniques. Adv. Anal. Chem. Instrum. 1965, 4, 117-210.

34. Swiech, O.; Dutkiewicz, P.; Wójciuk, K.; Chmurski, K.; Kruszewski, M.; Bilewicz, R. Cyclodextrin derivatives conjugated with aromatic moieties as pH-responsive drug carriers for anthracycline. J. Phys. Chem. B. 2013, 117, 13444-13450. [CrossRef]

35. Sanli, S.; Altun, Y.; Guven, G. Solvent Effects on pKa Values of Some Anticancer Agents in Acetonitrile-Water Binary Mixtures. J. Chem. Eng. Data 2014, 59, 4015-4020. [CrossRef]

36. Péan, C.; Djedaïni-Pilard, F.; Perly, B. Reliable NMR Experiments for the Determination of the Structure of Cyclodextrin Inclusion Complexes in Solution. In Proceedings of the Ninth International Symposium on Cyclodextrins, Santiago de Compostela, Spain, 31 May-3 June 1998; Labandeira, J.J.T., Vila-Jato, J.L., Eds.; Springer: Dordrecht, The Netherlands, 1999; pp. 659-662.

37. Wang, Z.; Landy, D.; Sizun, C.; Cézard, C.; Solgadi, A.; Przybylski, C.; de Chaisemartin, L.; Herfindal, L.; Barratt, G.; Legrand, F.X. Cyclodextrin complexation studies as the first step for repurposing of chlorpromazine. Int. J. Pharm. 2020, 584, 119391. [CrossRef]

38. Mora, L.; Chumbimuni-Torres, K.Y.; Clawson, C.; Hernandez, L.; Zhang, L.; Wang, J. Real-time electrochemical monitoring of drug release from therapeutic nanoparticles. J. Control Release 2009, 140, 69-73. [CrossRef]

39. Osa, T.; Matsue, T.; Fujihira, T. Cyclodextrin-nitrophenol system studied by polarography. Heterocycles 1977, 6, 1833-1839. [CrossRef] 